\title{
Evaluation of the Efficiency of Demineralizing Agents in Treatment with Removable and Fixed Orthodontic Equipment in Children
}

\author{
U. A. Fozilov
}

Bukhara State Medical Institute

\begin{abstract}
Before braces fixation, after professional oral hygiene, training in individual hygiene procedures, it was noted that the values of OHI-S and PHP indices significantly decreased in all subgroups. If the state of oral hygiene according to the OHI-S index was determined as good and did not exceed the value of 0.7 , then according to the PHR hygiene index - as satisfactory, being within the value of 1.6.
\end{abstract}

Keywords: Hard tissues of teeth, stabilize the development of initial caries, a set of diagnostic and preventive measures,

\section{INTRODUCTION}

1 month after the installation of the equipment, a significant increase in the OHI-S and PHR hygiene index values was found in all patients of the 1st and 2nd groups compared with the previous examination, which indicated a deterioration in the oral hygiene.

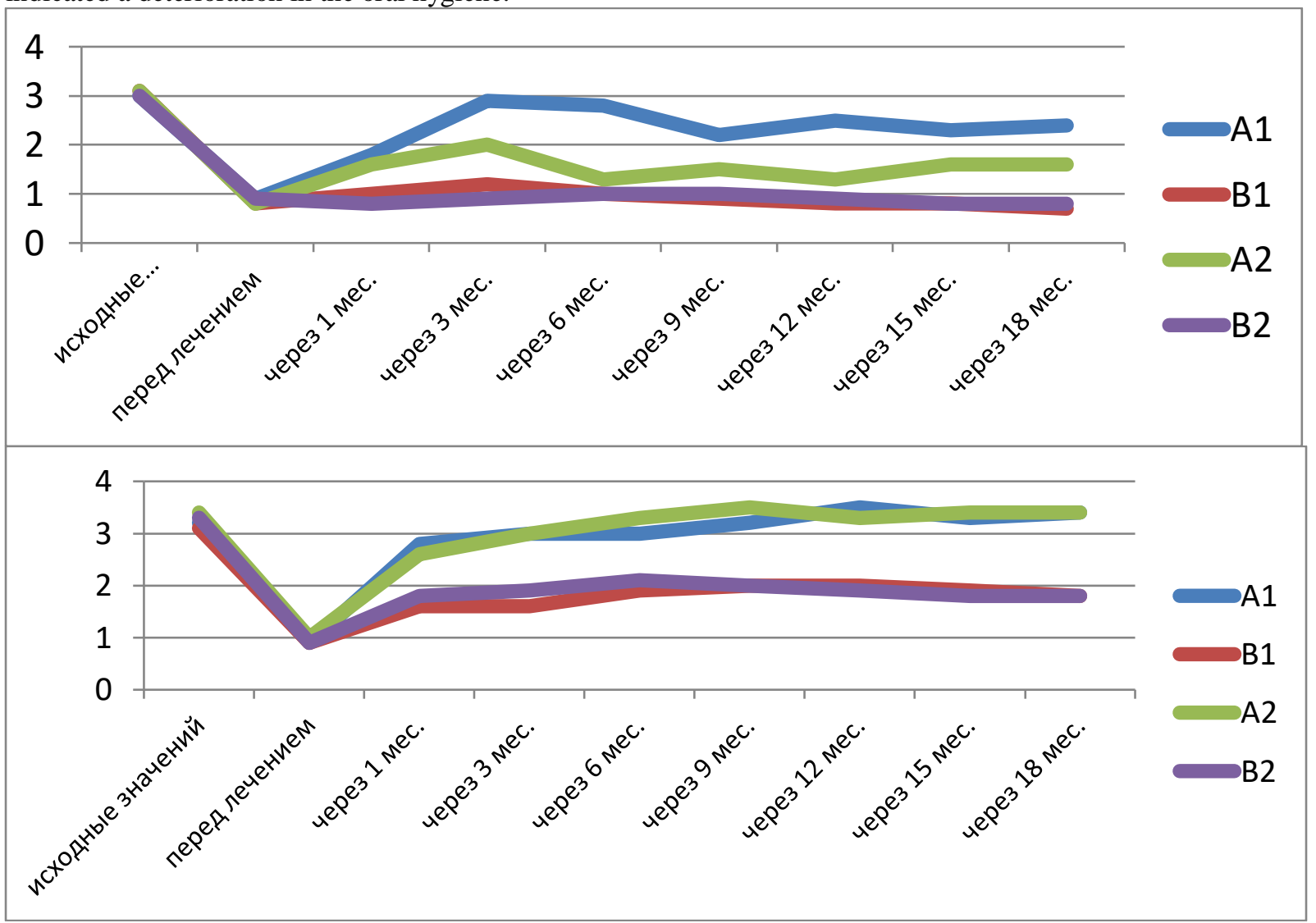

Fig. 1.Dynamics of hygiene indices (PHP and OHI-S) in the oral cavity during treatment

So, in the control subgroup A1 and B1, the indicators of the hygiene index according to the OHI-S index were 2.28 and 3.27 times higher, respectively, and according to the PHR index - 2.49 and 2.54 times, which characterized the hygienic state as unsatisfactory. ... In group A2 and B2, the values of hygienic indices did not exceed the initial data, which were assessed by the OHI-S index as a satisfactory level, and by the PHR hygiene index - as unsatisfactory.

Further observation revealed small fluctuations in the values of hygiene indices, which slightly differed from those in the prophylactic subgroups, remaining until the completion of the study at a satisfactory level according to the OHI-S index and at an unsatisfactory level according to the PHR index, but were significantly better than the values of the initial examination. 
In the control subgroups, the state of oral hygiene at the final examination according to the OHI-S and PHR hygiene indices according to the assessment criteria was unsatisfactory and exceeded the initial data. The lower values of hygiene indices in the prophylactic subgroups compared to the control ones are explained by professional oral hygiene and the use of therapeutic and prophylactic agents, which confirms the need for regular training, monitoring and monthly motivational education of patients in the process of orthodontic treatment.

The assessment of the development of inflammatory phenomena in the periodontal tissues during orthodontic treatment was carried out by determining the PMA index. Analyzing the data obtained, we can conclude that throughout the treatment, the state of periodontal tissues in all subgroups was less than $30 \%$, which corresponded to the assessment criterion of mild gingivitis.

With further observation, the inflammatory phenomena in the periodontal tissues persisted, but with a tendency to decrease (Fig. 2).

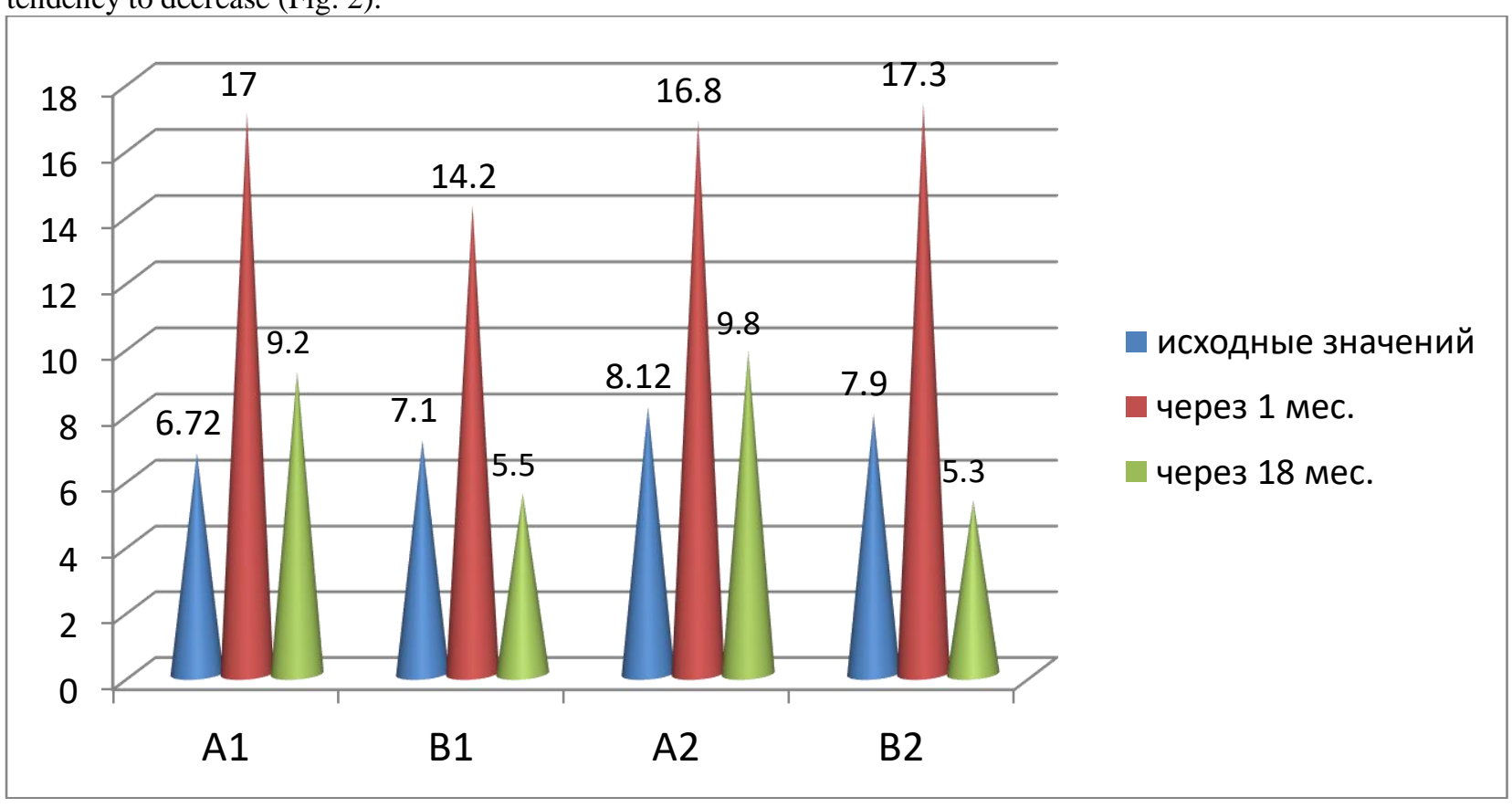

Fig. 2.Dynamics of the state of periodontal tissues (PMA) in the oral cavity during treatment

At the end of treatment, the PMA index values significantly differed in the prophylactic subgroups from the baseline data, but were significantly worse in the A1 and B1 control subgroups by $103.1 \%$ and $128.3 \%$, respectively.

According to the WHO criteria, indicators of the intensity of dental caries varied from low to high - in the range of 1.96 - 4.67. Before the study, all patients underwent oral cavity sanitation, after which only component $\mathrm{P}$. was present in the index structure.

A change in the indicators of the intensity of caries was revealed in all examined patients. Thus, in children of the A1 subgroup in the complex of preventive measures, the increase in carious cavities was, respectively, 00.17, while in the subgroup A2 - 0.09. In patients of the B1 subgroup, an increase in caries was found both on the chewing and on the contact surfaces of the teeth. In the control subgroups A1 and B1, where preventive measures were not carried out, the increase in carious cavities in patients was 0.17 to 1.57 , respectively.

Table 3. Intensity and reduction of dental caries in patients in the dynamics of treatment

\begin{tabular}{|l|c|c|c|c|c|c|}
\hline $\begin{array}{c}\text { Subgroups } \\
\text { Number of patients } \\
\text { with CPU }\end{array}$ & $\begin{array}{c}\text { Structure of } \\
\text { CPU }\end{array}$ & \multicolumn{2}{|l|}{$\begin{array}{c}\text { Caries } \\
\text { reduction (\%) }\end{array}$} & \multicolumn{2}{l|}{ Subgroups Number of patients with CPU } & $\begin{array}{c}\text { Structure of } \\
\text { CPU }\end{array}$ \\
\hline A1 & 26 & $4,84 \pm 0,13$ & $0,17 \pm 0,01$ & $4,67 \pm 0,39$ & 0 & \\
\hline A2 & 20 & $2,53 \pm 0,21^{*}$ & $0,09 \pm 0,007$ & $2,44 \pm 0,11^{*}$ & 0 & 90,2 \\
\hline B1 & 77 & $5,82 \pm 0,09$ & $1,57 \pm 0,06$ & $4,25 \pm 0,18$ & 0 & \\
\hline B2 & 78 & $2,25 \pm 0,19^{*}$ & $0,29 \pm 0,03$ & $1,96 \pm 0,07^{*}$ & 0 & 68,5 \\
\hline
\end{tabular}

Caries reduction after the use of the drug R.O.C.S. Medical Minerals "accounted for $90.2 \%$ and $68.5 \%$. 
The compliance of the tooth enamel with acid (TER test) during initial examination in patients with removable and non-removable orthodontic technologies was within the range of medium and high values, ranging from $58.32 \pm 1.37-68.13 \pm 1.32 \%$ (table 4.2 ).

To increase the acid resistance of enamel in prophylactic subgroups of the 2nd group, a course of treatment and prophylactic measures was carried out using R.O.C.S. Medical Minerals "and kapp. So, after using the drug "R.O.C.S. Medical Minerals"there was the greatest tendency for the TER test to decrease in relation to the initial inspection - by $27.8 \%$. This was due to an increase in the acid resistance of the enamel before fixing the removable and non-removable orthodontic appliances, which confirms the importance of this procedure.

Table 4. Indicators of changes in the TER test in patients in the dynamics of treatment

\begin{tabular}{|c|c|c|c|c|c|}
\hline $\begin{array}{c}\text { Subgroup TER test } \\
(\%)\end{array}$ & \multicolumn{4}{|c|}{ Initial Before treatment 1 month. 6 months 18 months } \\
\cline { 2 - 6 } & $\begin{array}{c}\text { Initial Before treatment } \\
\text { month. 6 months } 18 \\
\text { months }\end{array}$ & & & & \\
\hline A1 & $63,14 \pm 2,24$ & $61,35 \pm 1,17$ & $66,31 \pm 0,22$ & $72,46 \pm 0,38$ & $76,61 \pm 0,62$ \\
\hline B1 & $65,42 \pm 0,62$ & $49,21 \pm 3,29$ & $34,34 \pm 0,18$ & $36,93 \pm 0,32$ & $36,85 \pm 0,66$ \\
\hline B1 & $68,13 \pm 6,32$ & $48,91 \pm 2,65$ & $56,16 \pm 1,24$ & $57,52 \pm 0,16$ & $59,82 \pm 0,12$ \\
\hline B2 & $58,32 \pm 1,37$ & $47,16 \pm 0,58$ & $32,89 \pm 0,16$ & $35,31 \pm 0,13$ & $31,73 \pm 0,41$ \\
\hline
\end{tabular}

Note: * data reliability between treatment groups $\mathrm{A}$ and $\mathrm{B}(\mathrm{p}<0.05)$

It has been established that the processes of enamel demineralization in children with removable orthodontic appliances are directly dependent on the applied therapeutic and prophylactic agents. The results of the study convincingly showed the relationship of enamel demineralization processes with the used therapeutic and prophylactic agents (Fig. 4.).

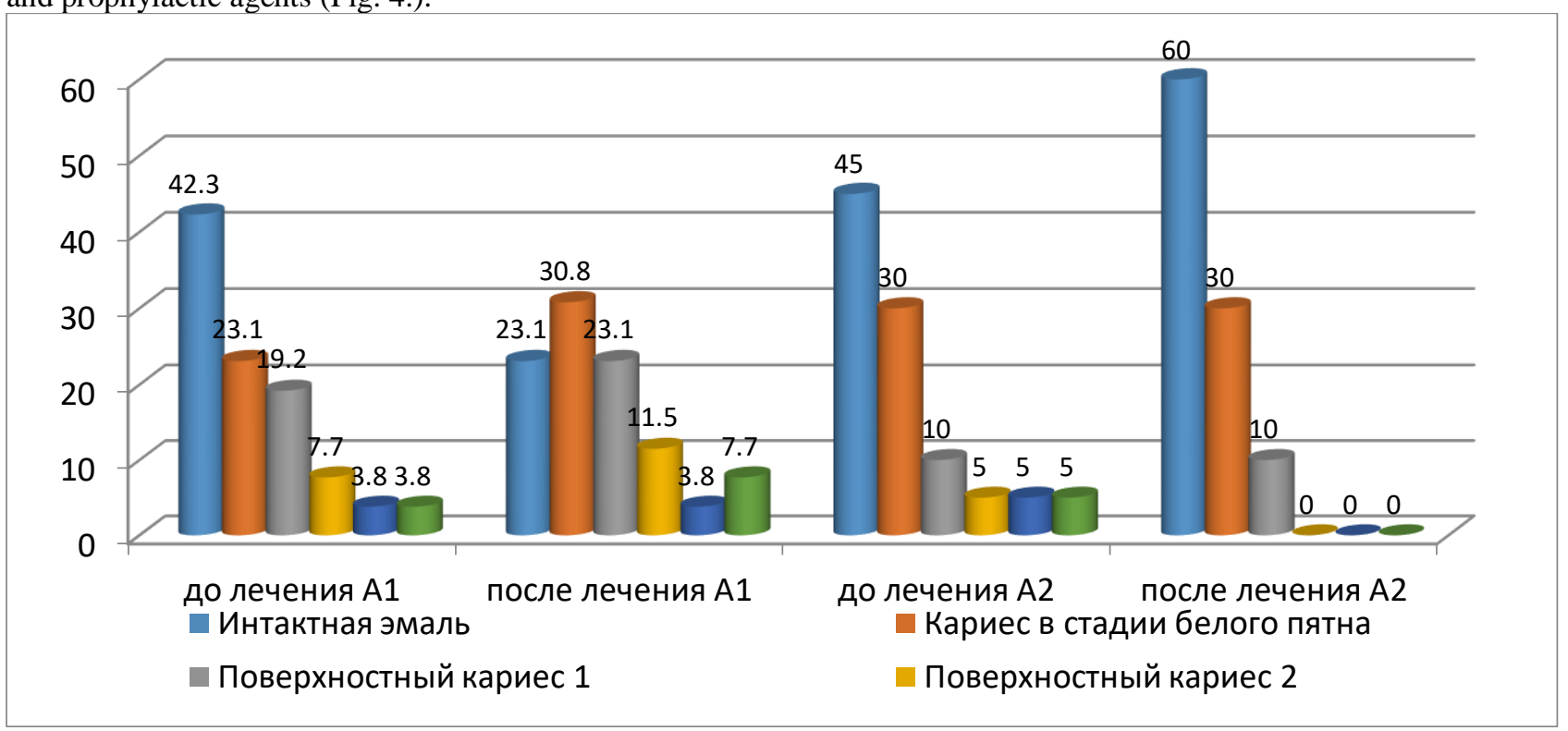

Fig. 4.Dynamics of indicators of clinical assessment of the state of dental hard tissues using light-induced fluorescence in patients with removable orthodontic appliances

So in subgroup B1, intact enamel was observed $20 \%$ more often than in group A1, and the development of medium and deep caries was not recorded, while in group A1 the development of a white spot was noted in $30.8 \%$, superficial caries 1 and 2 in 23,1 and $11.5 \%$, respectively, medium and deep caries in 3.8 and $7.7 \%$, respectively.

It has been established that the processes of demineralization of enamel around the braces in children are in direct proportion to the therapeutic and prophylactic agents used. The results of the study convincingly showed the relationship between the processes of demineralization of enamel from the used therapeutic and prophylactic agents. So, after 18 months in patients who used "R.O.C.S. Medical Minerals "and Kapp intact enamel were recorded in $83.3 \%$ of cases, which was significantly significant in relation to the data before treatment and group B1. Also, in group B2, medium and deep caries were not noted, and caries in the white spot stage was registered in $15.4 \%$ of cases, while superficial caries 1 - in $1.3 \%$ of cases, which is significantly low percentage in relation to the indicators of group B1 (Fig. 4.4). 


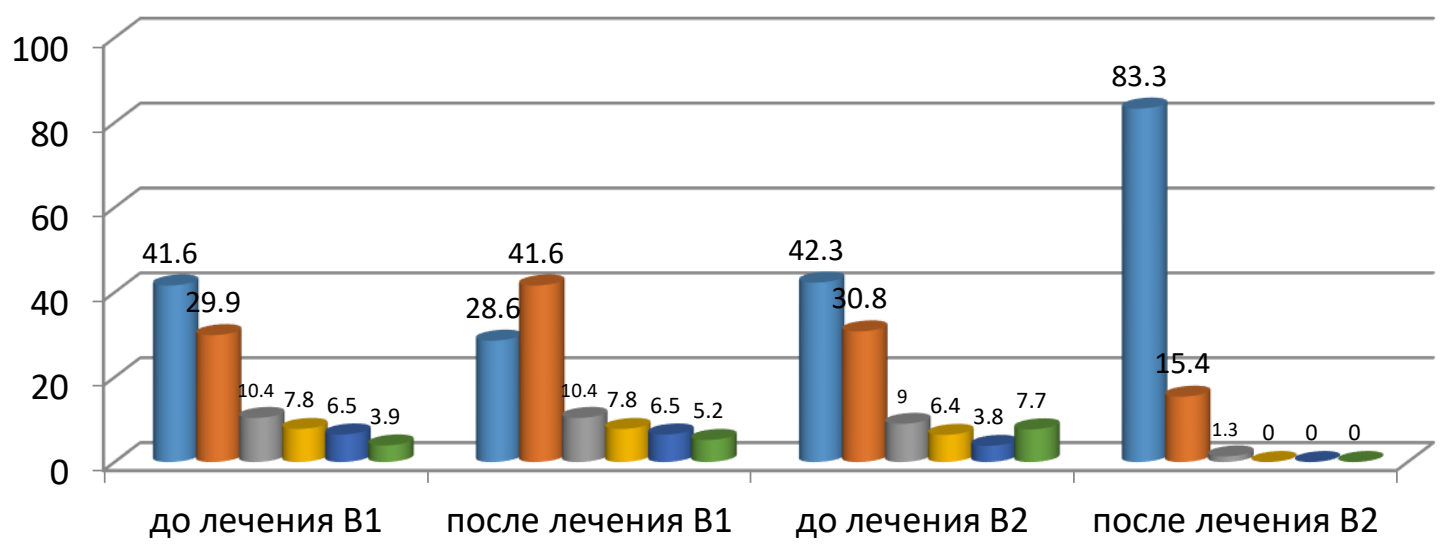

Интактная эмаль

Кариес в стадии белого пятна

Поверхностный кариес 1

Поверхностный кариес 2

Fig. 4.1. Dynamics of indicators of clinical assessment of the state of dental hard tissues using light-induced fluorescence in patients with fixed orthodontic appliances

Thus, the application of "R.O.C.S. Medical Minerals "and mouthguards and other remineralizing agents, help to increase the resistance of hard tissues of teeth, stabilize the development of initial caries, as evidenced by clinical assessment using the method of light-induced fluorescence.

Good results after 18 months were achieved in $93.3 \%$ of children from the A2 group and $90.5 \%$ from the B2 group, which was significant in relation to the indicators of the A1 and B1 groups $-68.9 \%$ and $65.8 \%$, respectively.

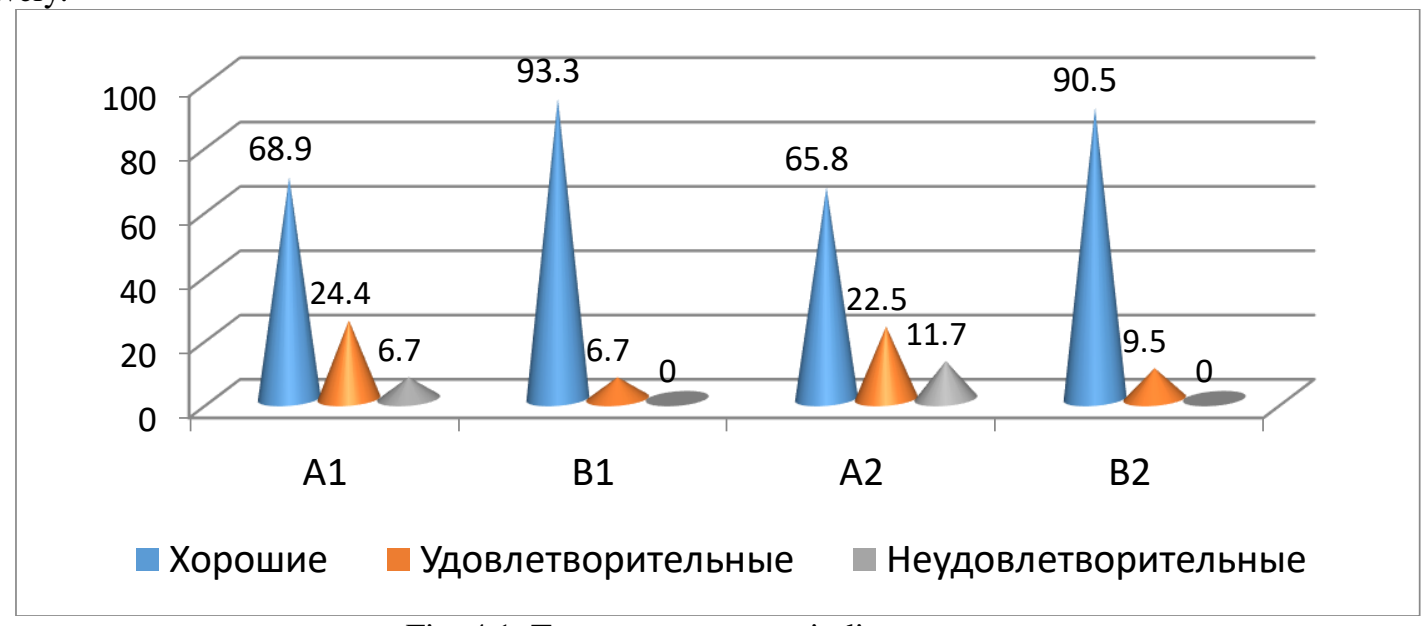

Fig. 4.1. Treatment outcome indicators

Thus, despite the introduction of a complex of therapeutic and prophylactic measures, the formation of new carious foci inevitably occurred, but in the main groups their number was 2.2 times less $(\mathrm{p}<0.05)$ than in the comparison groups, which indicates the effectiveness of its use in patients on orthodontic treatment with NOT and SOT for the prevention and treatment of caries.

Based on the foregoing, it should be noted that throughout our study in patients of the main group (A2, B2 subgroups) after anti-carious measures carried out for 1 month with the appointment of R.O.C.S. Medical minerals patients did not experience complete disappearance of all carious spots, despite the fact that this process is reversible (this is possibly due to the structure of hard tissues, inaccuracies in diet and inadequate adherence to all daily hygiene measures).

Thus, carrying out sanitary and educational work, individual and professional oral hygiene, along with the use of "R.O.C.S. Medical Minerals "and aligners allowed after 18 mesortodontic treatment to increase the resistance of hard tissues of teeth, to stabilize the development of initial caries, as evidenced by clinical assessment using the method of light-induced fluorescence. 
The developed and tested complex of preventive measures, including the local use of various therapeutic and prophylactic drugs and mouth guards, improves the hygienic state of the oral cavity, stabilizes the state of periodontal tissues and ensures a decrease in the growth rates of dental caries, which makes it possible to prevent the development of complicated forms of major dental diseases and contributes to an increase in quality of orthodontic care for children.

\section{REFERENCES}

1. Alexandrova L.L., Pustovoitova N.N., Yurchuk Yu.N. Diagnostics in therapeutic dentistry: a teaching aid. Minsk: BSMU, 2007.56 p.

2. Galiulina M.V., Ganzina I.V. Changes in the structural properties of saliva with changes in $\mathrm{pH} / /$ Dentistry. 2003. N 2.S. 22-44.

3. Kazeko L.A., Tikhonova S.M., Pustovoitova N.N. Modern approaches in the diagnosis of dental caries // Dental journal. 2007. N 4.P. 251-255.

4. Firla M. Biochemical rapid test designed to diagnose caries at the earliest stages of its development // New in Dentistry. - 2003. N 6.S. 26-30.

5. Safonova Yu.S. Methods of clinical and preclinical diagnosis of lesions of hard tissues of teeth // Dentistry News. - 2009. N 2.S. 59-62.

6. Shabanov A.N. Medical assistant's guide. M .: "Medicine", 1976. 487c.

7. Allen E, da Mata C, McKenna G, Burke F Minimal intervention dentistry and older patients. Part 1: Risk assessment and caries prevention // Dent Update. 2014. Vol. 41. P. 406-408.

8. Bennett T., Amaechi Emerging technologies for diagnosis of dental caries: The road so far // Journal of applied physics 2009. Vol. 14.P. 104-105.

9. Iain A. Pretty Caries detection and diagnosis: Novel technologies // Journal of dentistry 2006. Vol. 34. P. 727739.

10. Mackenzie L., Banerjee A. The minimally invasive management of early occlusal caries: a practical guide // Prim Dent J. 2014. Vol. 3. P. 34-41.

11. Roulet JF, Zimmer S. Professional prevention in the practice of the dentist. M .: MEDpress-inform, 2010.368 p.

12. Peshko A.A. Minimally invasive interventions in dentistry: strategies and technologies // Modern Dentistry. - 2008. N 1.S. 15-18.

13. Gordeeva N.O., Egorova A.V., Magomedov T.B., Venatovskaya N.V. Methodology for reducing the risk of pathology of hard dental tissues during orthodontic treatment with fixed equipment // Saratov Journal of Medical Scientific Research. 2011. T. 7. No. 1. S. 230-233.

14. Shumilovich B.R., Suetenkov D.E. The state of mineral metabolism of enamel depending on the method of preparation of hard tooth tissues in the treatment of caries // Dentistry of children and prevention. 2008. T. 7. No. 3. S. 6-9.

15. Firsova I.V., Suytenkov D.E., Davydova N.V., Oleinikova N.M. Interrelation and interdependence of the level of dental health and environmental factors // Saratov Journal of Medical Scientific Research. 2011. T. 7. No. 1. S. 239-245.

16. Usachev V.V., Bahrakh L.P., Suchkov S.G., Suetenkov D.E. New method of 3d-ultrasound diagnostics: possibilities of application in dentistry // Saratov Journal of Medical Scientific Research. 2006. T. 2. No. 3. S. 70-73.

17. Akulovich A.V., Suetenkov D.E., Yalyshev R.K., Konovalova A.Yu., Novak M.O. Evaluation of the effectiveness of using hygiene products based on calcium hydroxyapatite to reduce the sensitivity of tooth enamel // Dentistry of children and prevention. 2015.Vol. 14. No. 4 (55). S. 41-44.

18. Firsova I.V., Suetenkov D.E., Egorova A.V., Magomedov T.E., Kharitonova T.P., Davydova N.V., Lebedeva S.I., Bakhmeteva E.A., Gritsenko E.A. Indicators of dental health in children and adolescents in Saratov and the Saratov region // Saratov Journal of Medical Scientific Research. 2013.Vol. 9.No. 3.P. 484-486. 